\title{
Editorial \\ SUSTAINABLE LOW-COST WASTE MANAGEMENT: LEARNING FROM AIRLINES
}

Waste management around the world is characterised by a very wide range of levels of technology and service efficiencies. Clearly, socio-economic conditions (such as financial resources, technical education, infrastructures, etc.) are the main issues at the basis of these differences, manifested not only between industrialised countries and developing countries (DCs) but also within the same administrative areas, as is the case of the European Community (World Bank, 2018; Eurostat, 2019).

However, many other factors contribute towards these differences, including:

- Population density. This has a marked effect on waste quantities and, consequently, collection programs and volumes required for treatment and disposal of the waste. Indeed, the latter represents the main driving force for incineration as a prevailing waste management option in countries such as Japan, Singapore, Switzerland and many others, (Cossu, 2009).

- Waste quality. All decisions, any criteria, and recycling programmes in waste management are heavily based on this factor. Aspects such as presence of hazardous substances, their concentrations, purity of waste fractions might originate different solutions.

- Market for recycled waste fractions. This factor is closely linked to the industrial and socio-economic organization of the specific geographic area and to the local demand for products and services.

- Specific local situations (climate, topography, infrastructure, land planning, culture, etc.).

- Regulations. These may be of a varying nature (recommendation, address, prescription, etc.) and are capable of creating marked differences between one country and another.

This picture is further negatively complicated by the transfer of inappropriate technologies from one country to another. Traditionally (and still persisting today!), this issue was confined to developing countries where the implementation of advanced technologies designed in (and for) industrialised countries may prove inappropriate for various reasons (complexity, maintenance, lack of professional education and skilled technicians, operational costs, infrastructures, etc.), as widely highlighted in the literature (i.a. Grossule and Lavagnolo, 2018). However, improper use of technologies is also encountered in industrialised countries. In this case, the main factors impeding the use of specific technologies include an inadequate maturity of the technology, a non-homogenous waste quality and operational costs (energy and staff), in addition to a series of regulatory and bureaucratic issues. As an example, management problems experienced at several pyrolysis and gasification plants operated in Europe, including the lack of an adequate commissioning phase and survey of local conditions, are widely acknowledged.

Moreover, the transfer of inappropriate technologies may contribute towards creating so-called "Cathedrals in the desert", i.e. oversized facilities which are disconnected from the local reality, uneconomical, useless and frequently totally abandoned.

In numerical terms, more than $50 \%$ of global MSW production is still dumped or poorly landfilled, while the rest is treated using a series of different technologies (sanitary landfilling, recycling, anaerobic and/or aerobic stabilization, etc.) (World Bank, 2018), some of which may prove to be considerably complex and expensive. It was Laila Iskandar, working with the poor Zabbaleen recycling communities in Cairo, who famously said that, "waste management is far too important to be left to engineers; they build facilities which look like 4-star hotels".

Despite this inhomogeneous scenario in global waste treatment, the aims and objectives of a modern waste management strategy tend to align and coincide throughout all corners of the world.

This indeed represents the positive result achieved by an impressive growing globalization and consequent diffusion of culture and science, supported by the Internet, the media, conferences, scientific journals, common publishing targets in academic career, and exchange of scholars and students.

The aims and objectives of a modern waste management strategy can be summarized as follows:

- Industrial production with minimisation of waste generation by contrasting planned obsolescence, avoiding disposable goods and extending producer responsibility;

- Design and production of goods which promote reuse and facilitate recovery and recycling;

- Source segregation and reuse of waste fractions;

- Environmentally-sound waste collection programmes;

- Optimisation of consumption and recovery of energy and material resources from unavoidable waste;

- Sustainable management of recycling residues with 
control of contaminants and hazardous substances (this aspect is frequently underestimated in circular economy strategies);

- Adoption of a combination of technologies to synergise advantages (thermal treatment for combustibles, biological treatment for putrescibles, stabilization of mobile contaminants and sustainable landfill sinking);

- Control of short- and long-term emissions, prevention of diffuse emissions and control of greenhouse gasses (GHGs);

- Minimisation of health risks while paying strong attention to the public opinion and perception;

- Scientific monitoring of ecotoxicological effects arising from WM.

Based on the previously illustrated discrepancy between the inconsistent global WM scenario and the common views in modern WM strategies, in order to progress from the fictitious to reality, the following needs should be addressed:

- Increase in access worldwide to an appropriate waste management system;

- Pursuit of the aims and objectives of a modern waste management system by adopting affordable low cost solutions, with minimal expenditure of energy and material resources.

By successfully fulfilling these needs it may seem as though you are squaring the circle.

However.... airlines have already done something similar! In the not so distant past, flying was a privilege reserved for the wealthy. The availability however of fast-moving transport solutions represented a common interest for an increasing number of individuals.

It could indeed be argued that an identical discrepancy is encountered in waste management globally!

Of course, nowadays a lot more people can afford to travel by plane at a reasonable cost in safe conditions. The way in which this has been achieved should be an inspiration for the waste management world, merely in terms of analogy. Consequently, indirect disadvantages linked to the fact that transport is the fastest growing source of greenhouse gas emissions in the world, and that airline travel is a major part of this increase, are not considered here.

An overview of the main reasons underlying this success, focusing mainly on European low cost airlines which have successfully developed budget flight models, is given in Table1.

All features are substantially aimed at saving time and cutting costs, while at the same time guaranteeing rigorous safety conditions.

Leaving behind the airline metaphor, the following list of possible options could be taken into account for the purpose of turning solid waste management into a low-cost efficient system:

a) Any decision in WM should be based on a thorough and updated knowledge of waste quality variation in space and time; incredibly, this aspect is often neglected, resulting in inappropriate solutions and related costs; b) Flexible strategies linked to the local situation (e.g. refraining from conducting source segregation and separate collection of a specific fraction in the absence of an end user at a convenient distance);

c) Recycling programs should not defer to moralistic principles but should rather be based on urban mining concepts (recovery of resources should be reliable, realistic, affordable, with no demagoguery, economically and environmentally convenient);

d) Separate collection should not strive to achieve percentages in terms of amount of collected materials but rather in terms of quality of recycled material (collect less but of a better quality);

e) Organised involvement of the informal sector, associations, NGOs, etc.;

f) Simple technologies of proven efficiency should be preferred;

g) Technologies should be suited to the specific local conditions;

h) The same technology should be implemented throughout a given geographical area or country with the aim of saving on maintenance costs (spare parts supply, staff training, etc.);

i) In some specific situations the acquisition of services provided by experienced enterprises might be preferred over the direct acquisition and operating of facilities;

j) The so-called "Blue solutions" should be applied wherever possible, based on the principle whereby there is no need to spend/invest more to protect the environment, but rather lessons should be learned from the environment and from what nature has already created in order to establish new business and social capital;

k) A holistic approach should be adopted in spreading resources among the different WM steps (collection, transport, treatment, disposal);

I) Integrated approach to WM technologies with no ideological preclusion (shrewd combination of recycling, landfilling and thermal treatment) ;

m) The convenience of material suppliers should be assessed in terms of transportation (zero $\mathrm{km}$, repercussion on the community), use of resources (lower production of $\mathrm{CO}^{2}$, renewable energy, possibility of constant supply) and economic impact;

n) Economic return should be ensured through synergies with other economic/social activities (informal sector, recycling, reuse, etc);

o) Particular focus should be placed on the recycling of putrescible fractions prior to landfilling. Biological stabilization of residual putrescibles by in situ treatment should be opted for over expensive mechanical-biological off-site pre-treatment;

p) Landfill technologies should aim to drastically reduce the abuse of expensive geosynthetics, by substituting these with equivalent low-cost products (natural materials, suitable residues, etc.) when conveniently available locally;

q) Following traditional biological treatment, there is no need to remove residual COD, mainly made up of humic substances, from the treated MSW leachate. Requirements to comply with discharge standards set below 
TABLE 1: Overview of common features in low cost airline models and in the perspective of a low cost waste management system. LCC= Low cost carrier.

\begin{tabular}{|c|c|c|}
\hline Features & Adopted measures by LCC & Potential measures in WM \\
\hline No luxury or high cost items & $\begin{array}{l}\text { No video entertainment, thus no TV set and no operation of a } \\
\text { central audio or video station }\end{array}$ & $(a), b), c), f), g), k),(), o), p), q), r)$ \\
\hline Wise spending strategies & $\begin{array}{l}\text { - Well-proportioned fleet } \\
\text { - Bulk buying of same model of aircraft } \\
\text { - No frills on board }\end{array}$ & a), b), c), d), g), h), k), l), m), o), p), r), s), v), w) \\
\hline $\begin{array}{l}\text { Simplified and standardized technical } \\
\text { solutions }\end{array}$ & $\begin{array}{l}\text { Same reliable and well proven aircraft models: } \\
\text { Easy management and maintenance (professional staff are } \\
\text { trained on the same vehicle) } \\
\text { - } \quad \text { More convenient supply and storage of spare-parts } \\
\text { - Increased crew flexibility }\end{array}$ & $(c), f), j), h), o), q), t), u$ ) \\
\hline Simplified operation & $\begin{array}{l}\text { - Non-reclining seats (cheaper to buy and maintain } \\
\text { - No back pockets (less time for cleaning) }\end{array}$ & d), f), i), h), m), q), r), s), t) \\
\hline Staff saving & $\begin{array}{l}\text { - Young motivated staff } \\
\text { - Simplified training scheme (same aircraft model) } \\
\text { - Multi-tasking staff }\end{array}$ & e), h), i), k), n), t), u) \\
\hline Extra revenue generation & $\begin{array}{l}\text { - No free on-board services } \\
\text { - Some companies offer lottery tickets } \\
\text { - Separate fees for checked-in luggage and extra bags on } \\
\text { - Payment for seat reservation }\end{array}$ & b), d), e), j), n) \\
\hline Siting & $\begin{array}{l}\text { Small airports: } \\
\text { - } \quad \text { Low fees } \\
\text { High negotiation power }\end{array}$ & h), g), k), m), o), s), v), w) \\
\hline Energy saving & $\begin{array}{l}\text { Young aircraft fleets } \\
\text { - Baggage weight restrictions }\end{array}$ & $(c), d), j), m), q)$ \\
\hline Intense use of the facilities & $\begin{array}{l}\text { - Aircraft are used almost non-stop with rapid changeover } \\
\text { times } \\
\text { - Aircrafts return to the home hangar } \\
\text { - Overnight maintenance }\end{array}$ & $(h), i), 0), u), k$ ) \\
\hline Minimum overhead & $\begin{array}{l}\text { - Fuel bought in favourable market periods } \\
\text { - Direct online booking only }\end{array}$ & j), m), n), p) \\
\hline Time management & $\begin{array}{l}\text { - Every effort is made to reduce operation time } \\
\text { - On time flights promote the company image }\end{array}$ & $(b), h), i), m), o), p), t), u), v), w)$ \\
\hline Safety & - High safety records (money saving and good image) & i), j), m), t), u), v), w) \\
\hline
\end{tabular}

$150 \mathrm{mg} / \mathrm{L}$ for COD, generally based on Reverse Osmosis, should not necessarily be adopted;

r) Waste management should not be overregulated (as occurs increasingly in numerous industrialised countries) as this may represent an obstacle to a virtuous waste management strategy, in both economic and technical terms;

s) Regulations should be flexible, open to significant innovative scientific development and compatible with specific local situations;

t) Science-driven educational WM programs in schools and universities should be increased, accessible to all, including local administrators;

u) Standardised and simplified operational and maintenance manuals should be provided to all technical staff;

v) An organised reasonable involvement of stakeholders in taking decisions prior to implementation of WM strategies might avoid costly opposition and protests afterwards;

w) Communication tools aimed at contrasting potentially misleading fake news (possibly resulting in unnecessary opposition by the public and related costs) should be developed.

To conclude, low cost strategies do not necessarily im- ply a reduced performance in protecting the environment and the public health; they should however represent a cost-effective solution intended to extend access of the populations worldwide to sustainable waste management systems.

Squaring the circle? Prepare for take-off!!!

Raffaello Cossu *, Valentina Grossule and Maria Cristina Lavagnolo DICEA, Department of Civil, Environmental and Architecture Engineering, University of Padova, Italy

* raffaello.cossu@unipd.it

\section{REFERENCES}

Cossu R. (2009). Driving forces in national waste management strategies, Waste Management 29, 2797-2798

Eurostat (2019) waste statistics. https://ec.europa.eu/eurostat/statistics-explained/index.php/Waste_statistics (Accessed on the 15th, June, 2019).

Grossule V., Lavagnolo M.C. (2018). From 3R to 3S: an appropriate strategy for developing countries. Detritus, 4, 1-3. https://doi. org/10.31025/2611-4135/2018.13749 @ Cisa Publisher. Open access article under CC BY-NC-ND license

Kaza S., Yao L. C., Bhada-Tata P., Van Woerden F. (2018). What a Waste 2.0 : A Global Snapshot of Solid Waste Management to 2050. Urban Development; Washington, DC: World Bank. (c) World Bank. https://openknowledge.worldbank.org/handle/10986/30317 